\title{
Changing crop management improves farm level productivity and profitability for smallholder farmers in northern India
}

\author{
$\underline{\text { Y.G. Beletse }}^{\mathrm{a}}{ }^{\mathbb{D}}$, A.M. Laing ${ }^{\mathrm{b}}$, D.B. Prestwidge ${ }^{\mathrm{b}}$, M.K. Gathala ${ }^{\mathrm{c}}$, N. Subash ${ }^{\mathrm{d}}$ and A.C. Liedloff ${ }^{\mathrm{e}}$ \\ ${ }^{a}$ CSIRO Agriculture \& Food, Canberra, ACT; ${ }^{b}$ CSIRO Agriculture \& Food, Brisbane, Qld 4067, Australia, \\ 2601, Australia; ${ }^{c}$ CIMMYT, Dhaka, Bangladesh; ${ }^{d}$ ICAR Meerut, Uttar Pradesh, India; ${ }^{e}$ CSIRO Land \& \\ Water, Darwin, NT 0822, Australia \\ E-mail: yacob.beletse@,csiro.au
}

\begin{abstract}
Cropping practices such as diversification, intensification and conservation agriculture-based management, which provide productivity and economic benefits to farmers, have been tested across northern India; however, farmers' adoption rate of these technologies remains low. A key reason for poor adoption rates of improved practices is the difficulty in enabling farmers, extension officers and policymakers to understand the likely farm-level trade-offs and benefits of these practices. Simulation models which integrate resources and activities (i.e. crop and livestock production, economics, and labour availability) across the whole farm can be used to examine the trade-offs and benefits of alternative farming systems. This study examined changes in farm-level productivity and profitability over a 20 -year simulation window under a range of cropping system interventions for four farm typologies found in smallholder farming systems across the northern Indian cereal-growing belt. The farm typologies studies are: well-resourced, moderately-well resourced, moderately-poorly resourced and poorly-resourced farming systems. The baseline management for each farm typology was a rice-wheat cropping system under conventional crop management practice combined with dairy production. Alternative cropping system scenarios were (1) intensification (inclusion of a third crop, mungbean); (2) diversification (replacing wheat with maize); (3) intensification and diversification combined (intercropping spinach with maize); and (4) introducing conservation agriculture (CA) management practices in all cropping systems. The same livestock management was maintained in all scenarios, with mating of cows staggered throughout the year to try to maintain continuous milk supply. The effects of intensification and CA were examined for all four typologies; diversification and intensificationand-diversification combined were examined for the two more marginal typologies only. For all scenarios, farming system economic productivity, gender-disaggregated labour requirements, and the farm cash balance were simulated monthly and then reported annually. Intensifying the cropping system increased farm economic productivity by $16-19 \%$, diversification increased productivity by $21-40 \%$, intensification combined with diversification increased farm economic productivity by $19-39 \%$, and CA practices improved economic productivity in all combinations of cropping system scenario and farm typology. CA practices reduced overall farm labour requirements, with savings greater for men than for women. Diversification did not affect labour demand, while intensification increased labour requirements, especially for men. Annual farm cash balances increased when cropping systems were intensified by introducing a third consecutive (mungbean) or concurrent (intercropped spinach) crop and in cropping systems under CA practices. This study demonstrates the ability of biophysical whole-farm models to quantify the likely medium-term effects of a range of cropping system management options in terms of farm economics and labour requirements. This simulation modelling approach has the potential to enable farmers, extension officers, policymakers and others to examine the benefits, risks and trade-offs of different management options within smallholder farming systems.
\end{abstract}

Keywords: CLEM, conservation agriculture, intensification and diversification, farming systems, simulation modelling 
Beletse, Laing et al., Farm-level effects of changing crop management using the Crop Livestock Enterprise Model (CLEM) in India

\section{INTRODUCTION}

In northern India, approximately $20 \mathrm{~m}$ ha is cropped, and farmers typically grow two crops a year. A common rotation is a wet season rice crop followed by a dry season irrigated cereal crop, which has conventionally been wheat (Gathala et al., 2020). Smallholder farmers depend on integrated crop-livestock farming systems for their livelihoods, with large ruminants kept predominantly for milk production. Although widespread, the ricewheat rotation has been shown to be inefficient (Gathala et al., 2020). A number of improved crop management practices (e.g. crop intensification or conservation agriculture practices such as no tillage, increased stubble retention, crop diversification; Gathala et al., 2020) offer potential to improve cropping system productivity and profitability (Gathala et al., 2020), but adoption remains very low in smallholder farming systems. A key reason for poor rates of adoption of improved practices is the difficulty in enabling farmers, extension officers and policymakers to understand the likely farm-level trade-offs and benefits, e.g., cost and labour savings, of the practices (Ward et al. 2018).

One way to demonstrate the potential farm scale value of alternative crop management is by using simulation models to dynamically integrate crop, livestock, labour, and economics under different cropping scenarios. The purpose of this study was to examine whole-farm productivity, profitability, and labour demand of four farm typologies from the northern India grain cropping belt. We used a farming systems model, the Crop Livestock Enterprise Model (CLEM), to compare baseline and alternative crop management scenarios over 20 year simulation runs.

\section{MATERIALS AND METHODS}

Four typologies, covering a wide diversity of smallholder farms across the north Indian cereal-growing belt, were developed based on those identified by Lopez-Ridaura et al. (2018). These typologies illustrate some of the heterogeneity observed in north Indian farming systems in terms of cropping system practices, livestock ownership, and socio-economic conditions (Table 1). Each farm typology was described in terms of its farm resources (e.g. land area, savings, household labour, ruminants (age, sex, milking status), the animal food store; the crop, fodder and livestock management required to manage these resources; and the farm cash flow. In no typology was labour a constraining resource. For each farm typology women spent more person-days on tasks than men, as they had primary responsibility for livestock husbandry and contributed to crop cultivation. Men were primarily responsible for crop cultivation.

Table 1. Key details of the four farm typologies used in the analyses

\begin{tabular}{|c|c|c|c|c|c|c|}
\hline Typology & Description & $\begin{array}{l}\text { Land } \\
\text { area } \\
\text { (ha) } \\
\end{array}$ & $\begin{array}{l}\text { Economic } \\
\text { resources } \\
(\text { AUD })^{1} \\
\end{array}$ & $\begin{array}{l}\text { Irrigation } \\
\text { subsidy } \\
(\%) \\
\end{array}$ & Machinery & $\begin{array}{l}\text { Milking } \\
\text { animals }\end{array}$ \\
\hline WR & $\begin{array}{l}\text { Well } \\
\text { resourced }\end{array}$ & 3 & 938 & 60 & Owned & 6 \\
\hline MWR & $\begin{array}{l}\text { Moderately } \\
\text { well } \\
\text { resourced }\end{array}$ & 2.5 & 563 & 50 & Owned & 5 \\
\hline MPR & $\begin{array}{l}\text { Moderately } \\
\text { poorly } \\
\text { resourced }\end{array}$ & 1.7 & 100 & 30 & Hired & 4 \\
\hline PR & $\begin{array}{l}\text { Poorly } \\
\text { resourced }\end{array}$ & 1.2 & 50 & 20 & Hired & 3 \\
\hline
\end{tabular}

${ }^{1} 1 \mathrm{AUD}=53.3 \mathrm{INR}$ in August 2021

We examined the effects of imposing alternative cropping system practices on each typology, in terms of farm productivity, labour requirements, and profitability. These alternative crop management practices included intensifying the baseline cropping system; introducing CA crop management; and, for some typologies only, diversifying the cropping system. We used the Crop Livestock Enterprise Model (CLEM), a biophysical model which facilitates examination of the crop, livestock, labour and economic components of farm enterprises. In each typology the baseline (B) cropping system was a rice-wheat cropping system with dairy ruminants (Table 2). Other cropping systems explored intensifying the baseline to a rice-wheat-mungbean system (I), diversifying to a rice-maize (D) system, combining intensification and diversification (D+I) in a ricemaize+spinach system where maize was intercropped with spinach. These cropping systems were simulated under the conventional crop management practices widespread across north India; additional simulations explored the effects of conservation agriculture (CA) practices on the B, I and D cropping systems. The B, I, $\mathrm{B}+\mathrm{CA}$, and $\mathrm{I}+\mathrm{CA}$ simulations under conventional and CA management were applied across all typologies, while the $\mathrm{D}, \mathrm{D}+\mathrm{I}$ and $\mathrm{D}+\mathrm{CA}$ simulations were applied to the MPR and PR typologies only. Livestock management was consistent across all simulations and had the primary aim of maintaining year-round milk 
Beletse, Laing et al., Farm-level effects of changing crop management using the Crop Livestock Enterprise Model (CLEM) in India

production where possible, using on-farm resources as the primary source of animal feed. When these were depleted additional feed was purchased as needed.

Table 2. Cropping systems used in the farm simulations

\begin{tabular}{l|l|l}
\hline Simulation & Cropping system description & Crop management \\
\hline $\mathrm{B}$ & Baseline rice-wheat & $\begin{array}{l}\text { Crops conventionally managed: fields tilled before } \\
\text { crop establishment, rice manually transplanted into } \\
\text { compacted (puddled) soil, and crop residues } \\
\text { removed from fields and used as animal feed }\end{array}$ \\
\hline $\mathrm{I}$ & $\begin{array}{l}\text { Intensification to rice-wheat- } \\
\text { mungbean }\end{array}$ & $\begin{array}{l}\text { All crops grown under conventional management; } \\
\text { mungbean grown sequentially after wheat }\end{array}$ \\
\hline $\mathrm{D}$ & Diversification to rice-maize & $\begin{array}{l}\text { Both crops grown under conventional } \\
\text { management }\end{array}$ \\
\hline $\mathrm{D}+\mathrm{I}$ & $\begin{array}{l}\text { Diversification and intensification to } \\
\text { rice-maize+spinach }\end{array}$ & $\begin{array}{l}\text { All crops grown under conventional management; } \\
\text { spinach grown concurrently with maize }\end{array}$ \\
\hline I+CA & Rice-wheat under CA & $\begin{array}{l}\text { Rice and wheat crops grown following CA } \\
\text { principles: fields untilled, crops mechanically } \\
\text { established, and crop residues retained in the field }\end{array}$ \\
\hline $\mathrm{D}+\mathrm{CA}$ & Intensification under CA & $\begin{array}{l}\text { Rice, wheat and mungbean all grown under CA } \\
\text { management; mungbean grown sequentially after } \\
\text { wheat }\end{array}$ \\
\hline
\end{tabular}

CLEM uses input data on the crop, forage, livestock, initial cash balances, and available labour of a farming system to simulate whole farm operations in both subsistence smallholder agricultural systems. CLEM simulates the performance over the medium-to-long-term of different farming system scenarios, which can be compared: it is not an optimisation model. CLEM expands upon the functionality of the earlier farming systems model the Integrated Analysis Tool (IAT, MacDonald et al., 2019; Lisson et al., 2010), which has been widely used in smallholder farming systems. More information on CLEM is available at www.apsim.info/clem

Input data to parameterise the farming systems were sourced from a) cropping system simulations previously undertaken across north India using the Agricultural Productions Systems sIMulator (APSIM; Holzworth et al. 2014); b) local experts in north Indian farming systems; and c) government websites for crop and input prices. Baseline simulations were validated using the expert opinions of research scientists from CIMMYT in South Asia and the Indian Council of Agricultural Research, following the method described in McDonald et al. (2019) and Sterman (2000). Simulations were run for 20 continuous years, covering a time period from 1997 to 2016.

For all scenarios the farming system economic productivity, labour necessary to conduct all management tasks and the farm cash balance were simulated monthly. Farming system economic productivity was the value of farm output minus the value of farm system inputs. Farm system output was the sum of the economic value of the grain and milk yields. While in reality only the farm surplus after feeding the household would be sold, the economic value of the entire grain and milk yields was used here to facilitate analysis. Farm system inputs were the cost of producing both crop and milk yields and the economic value of the labour required on the farm to tend crops and livestock and to produce grain and milk. The simulations do not include post-farm gate labour, e.g. to take produce to market. Availability of on-farm labour was disaggregated by gender but there was no difference in the cost of men's and women's labour. The farm cash balance was the cash remaining once annual expenses were subtracted from annual income. The farm cash balance did not account for machinery depreciation or maintenance costs, non-agricultural household expenditure such as transport, education, or health, or for debt payments.

To simplify comparison among different alternative management scenarios, economic productivity, labour requirements and farm cash balance of each scenario were calculated relative to the baseline simulation of each typology. Analysis and graphical analysis were performed with R version 3.3.0 (R Core Team, 2021).

\section{RESULTS AND DISCUSSION}

\subsection{Farming system productivity}

The economic productivity, defined here as the ratio of the value of farm outputs to the value of production inputs, of the six alternative scenarios relative to the baseline are presented in Figure 1. Inputs and outputs were considered seasonally for crops and annually for livestock; no capital assets were included in financial calculations, thus enabling a comparison of the effects of management practices without confounding variables. 
Beletse, Laing et al., Farm-level effects of changing crop management using the Crop Livestock Enterprise Model (CLEM) in India

Farm profitability followed a similar trend to economic productivity (data not shown) and overall both economic farm productivity and profitability were higher under improved crop management.

\section{Cropping system intensification and diversification options}

Intensifying the cropping system increased farm productivity above the baseline by $17 \%$ in the WR typology, by $19 \%$ in both the MWR and MPR typologies, and by $16 \%$ in the PR typology. In these triple-cropped systems, the productivity again increased under CA management (I+CA) by $71 \%$ in the WR typology, by $45 \%$ in the MWR typology, by $36 \%$ in the MPR typology, and by $30 \%$ in the PR typology, relative to the intensified cropping system without CA. The higher economic productivity in the WR and MRW typologies was a result of greater resource (fertiliser, irrigation, weed control) availability in these farming systems.

Diversifying the cropping system from the baseline to the rice-maize system increased farm economic productivity by $21 \%$ in the MPR and by $40 \%$ in the PR typologies. Diversification was more productive than intensification, as maize is a more productive crop than wheat, and the additional (grain or economic) productivity from maize alone was often greater than the (grain or economic) productivity from wheat and mungbean combined.

Combining intensification and diversification in the $\mathrm{D}+\mathrm{I}$ (rice-maize+spinach) cropping system to did not increase average economic productivity in the MPR and PR typologies relative to the diversified rice-maize system. Compared to the conventional baseline farming system, however, the farm-level productivity of the $\mathrm{D}+\mathrm{I}$ cropping system was $19.4 \%$ higher in the MPR and $39 \%$ higher in the PR typologies. Combining a highly productive cereal crop with a vegetable crop such as spinach provides additional sources of human nutrition for the farm household as well as extra cash income, in particular for female farmers who conventionally cultivate vegetable crops.

\section{Conservation agriculture}

Introducing CA management to the rice-maize cropping system increased farm economic productivity by $158 \%$ in the MPR and by $76 \%$ in the PR typologies. CA practices increase the plant-available soil water relative to conventional management practices and improve yields, particularly in irrigated dry-season crops such as wheat, maize and mungbean (Gathala et al., 2020). In all farming systems the introduction of CA management increased cropping system grain productivity and hence farming system economic productivity.

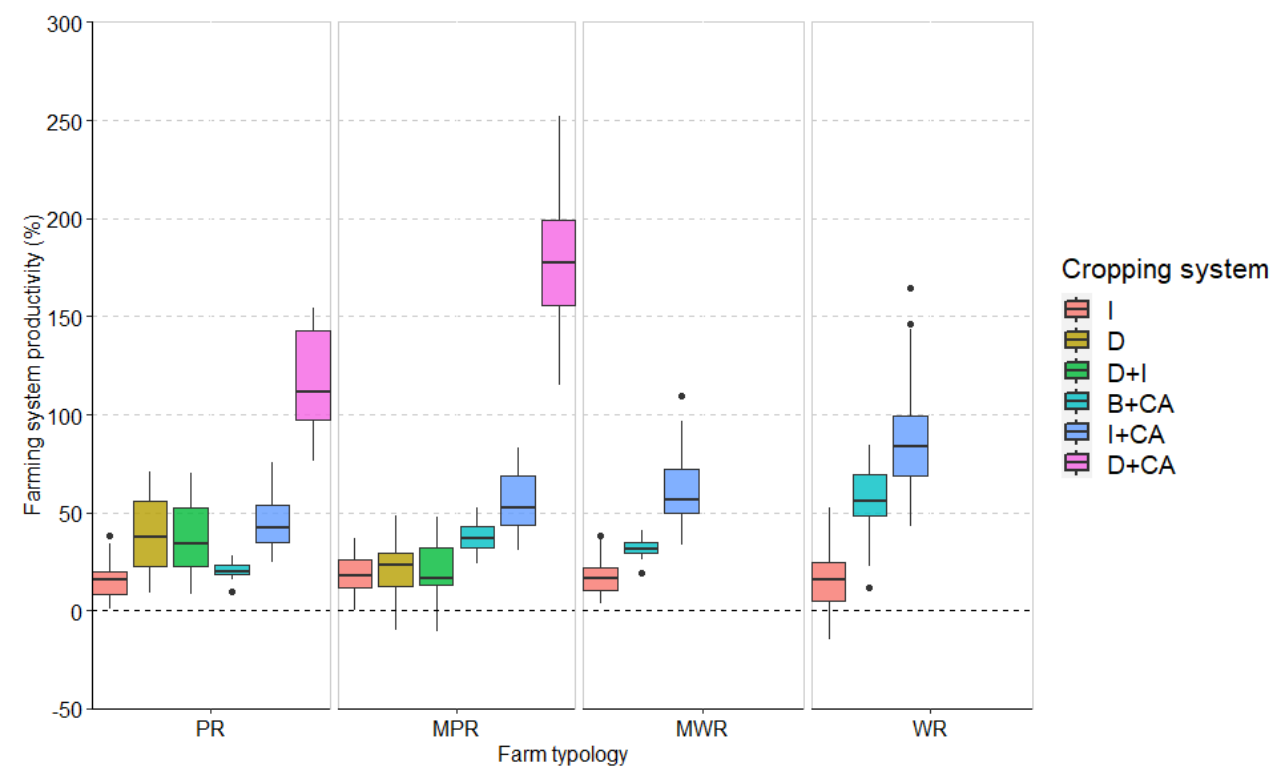

Figure 1. Annual farming system economic productivity for four farm typologies under six cropping systems, relative to a baseline rice-wheat in each typology. The lower horizontal line of each box is the $25^{\text {th }}$ percentile, the upper horizontal line is the $75^{\text {th }}$ percentile, the horizontal line within each box is the median.

Whiskers are $1.5 \mathrm{x}$ the interquartile range from the $25^{\text {th }}$ and $75^{\text {th }}$ horizontal lines; dots show outliers.

$\mathrm{I}=$ intensification, $\mathrm{D}=$ diversification, $\mathrm{I}+\mathrm{D}=$ intensification + diversification, $\mathrm{CA}=$ conservation agriculture

\subsection{Labour requirements}

The change in men's and women's labour required for each farm typology under different crop management practices, relative to the rice-wheat baseline is shown in Figure 2.

\section{Cropping system intensification and diversification options}


Beletse, Laing et al., Farm-level effects of changing crop management using the Crop Livestock Enterprise Model (CLEM) in India

Intensifying the cropping system increased men's and women's labour requirements in all farm typologies. This increase in labour was greater for men (ranging from $+8.3 \%$ in the MWR typology to $+31.2 \%$ in the PR typology) as most of the extra crop management tasks arising from an additional crop (e.g. land preparation, fertiliser, irrigation) were undertaken by men. The third crop increased women's required labour by between $+2.6 \%$ (WR) and $+7.9 \%(\mathrm{PR})$ because women made smaller contributions to crop production than men.

Diversifying the baseline rice-wheat system into rice-maize had variable effects on men's and women's labour. The diversified system required $+27.4 \%$ more male labour and $+7.4 \%$ more female labour in the MPR typology, while in the PR typology both male and female labour requirements were unchanged. This was a result of the different amounts of land cultivated under wheat and maize in each farm typology.

Further intensifying the rice-maize system into rice-maize+spinach did not change the labour requirements for men but increased women's labour by $+55.2 \%$ in the MPR typology and by $+10.5 \%$ in the PR typology. The cultivation of vegetables, e.g., spinach, is primarily undertaken by women.

\section{Conservation agriculture}

The introduction of CA practices (in any cropping system) had the greatest savings in labour, for both men and women. Under CA land preparation is eliminated as there is no ploughing or tilling prior to crop establishment, and mechanised crop establishment significantly reduces the labour required at sowing or transplanting. As well, weeds are usually chemically managed. Reductions in farming system labour requirements for cropping systems under CA were higher for men (e.g. for the WR typology labour savings of $35 \%$ in the baseline ricewheat system under CA compared to the traditionally-managed rice-wheat baseline; or of $32 \%$ in the intensified rice-wheat-mungbean under $\mathrm{CA}$ system, relative intensified system under traditional management) than for women (e.g. in the WR typology savings of $15 \%$ in both the baseline under CA and the intensified rice-wheatmungbean system under CA, relative to the traditionally-managed tice-wheat baseline and the traditionally managed intensified systems, respectively). This was because women's labour included livestock husbandry which was negatively affected by CA management as more time was required obtaining animal feed once crop residues were retained in the field.

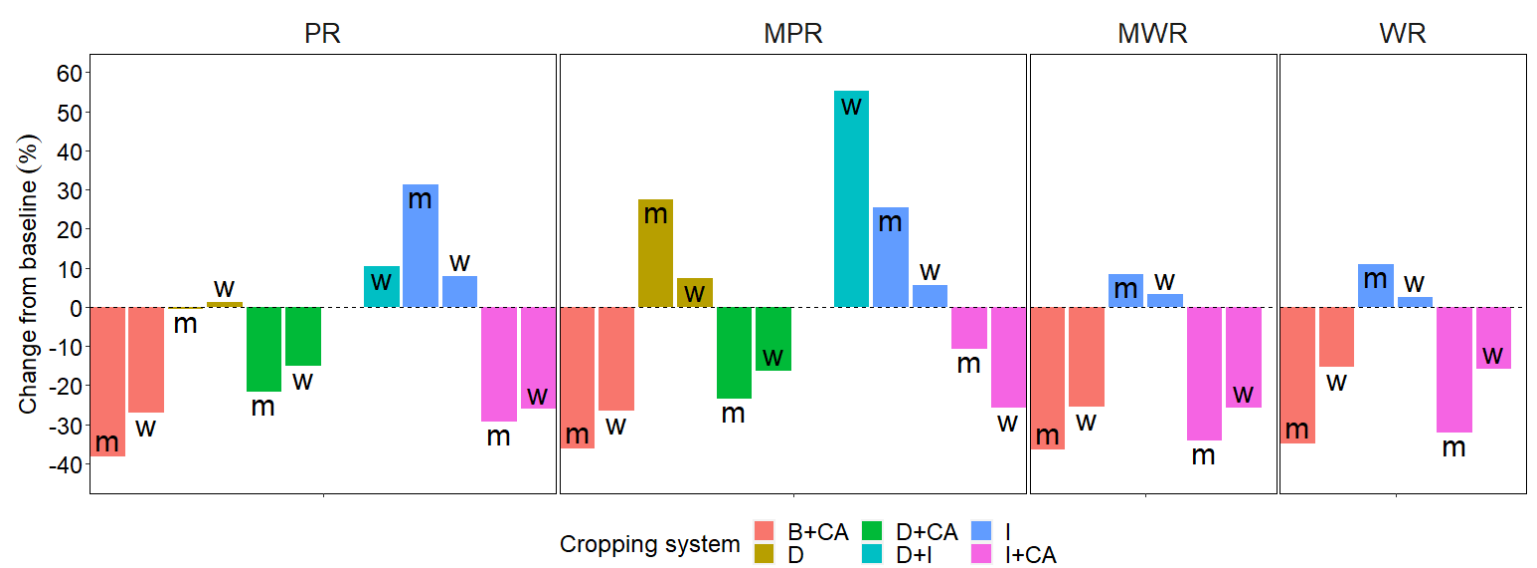

Figure 2. Percentage change in men's and women's labour requirements for each farm typology under six cropping system scenarios relative to the baseline. $\mathrm{m}=\mathrm{men}, \mathrm{w}=$ women; $\mathrm{I}=$ intensification, $\mathrm{D}=$ diversification, $\mathrm{I}+\mathrm{D}=$ intensification + diversification, $\mathrm{CA}=$ conservation agriculture

\subsection{Farm cash balances}

The annual average farm cash balance was highest in the WR typology and lowest in the PR typology, regardless of the cropping system simulated (Figure 3). Comparing results under the baseline (which had the lowest cash balances across all scenarios and typologies), for the WR typology, the annual average farm cash balance was 400,000 INR ha- $\mathrm{y}^{-1}\left(7,330 \mathrm{AUD} \mathrm{ha}^{-1} \mathrm{y}^{-1}\right)$, with a coefficient of variation (CV) between 3-4\%, and for the PR typology the annual average farm cash balance was 35,000 INR ha'-1 $\mathrm{y}^{-1}\left(640 \mathrm{AUD} \mathrm{ha}^{-1} \mathrm{y}^{-1}\right)$, with a CV between $17-24 \%$.

Intensification, diversification, and the combination of intensification and diversification together all increased annual average farm cash balances relative to farm cash balances achieved in the baseline cropping system (Figure 4).

\section{Cropping system intensification and diversification options}

Intensifying from the baseline to the rice-wheat-mungbean system improved farm cash balances by $12 \%$ in the WR typology, by $7 \%$ in the MWR typology, by $8 \%$ in the MPR typology, and by $18 \%$ in the PR typology. 
Beletse, Laing et al., Farm-level effects of changing crop management using the Crop Livestock Enterprise Model (CLEM) in India

Despite the additional crop inputs and labour required to produce a third crop, this cropping system contributed to a more profitable farming system for all farm types. As well, intensifying the baseline cropping system reduced the cash balance variability by $3 \%(\mathrm{CV}=3 \%)$ in the WR typology, by $5 \%$ in the MPR typology and by $20 \%$ in the PR typology.

Diversifying from the baseline to the rice-maize system increased farm cash balances by $11 \%$ in the MPR typology and by $34 \%$ in the PR typology, reflecting the greater yields achieved from maize rather than wheat, and the higher cash price of maize. Diversifying increased the cash balance variability by $24 \%$ in the PR typology, whereas in the MPR typology, where farmers have relatively larger land sizes, variability was $5 \%$.

Intensifying and diversifying from the baseline to the rice-maize+spinach system increased the farm cash balances by $22 \%$ in the MPR typology and by $66 \%$ in the PR typology. Compared to the intensified rice-wheatmungbean cropping system, growing the maize and spinach crops concurrently through intercropping enabled farmers to generate additional revenue from a third crop with fewer input costs (labour, fertiliser, irrigation) than were required incurred when the third crop was grown consecutively. Farm cash balance variability was $19 \%$ for the PR typology, showing that intensification and diversification are relatively high risk for this typology where land size and resources are limited.

\section{Conservation agriculture}

Conservation agriculture practices also contributed to increased farm cash balances. Relative to the baseline, the rice-wheat system under CA achieved a 4\% higher cash balance in the WR typology, a 3\% higher balance in the MWR and MPR typologies, and a $12 \%$ higher balance in the PR typology. Combining CA with intensification increased cash balances above the baseline by $12 \%$ in the WR typology, by $7 \%$ in the MWR typology, by $8 \%$ in the MPR typology and by $18 \%$ in the PR typology. These increases in farm cash balances reflect the lower labour requirements and higher cropping system productivity achieved under CA practices. CA increased farm cash balance variability by $17 \%$ in the PR typology, and by $3-5 \%$ in the MPR, MWR and WR typologies, indicating that the potential for high economic benefits of CA in the PR typology comes with risks in terms of relatively high farm cash balance variability.

While the average annual farm cash balances were lowest for the PR typology, the effect of the improved crop management options was greatest, with increases ranging from 10\% (in the intensified cropping system) to $66 \%$ (in the intensified and diversified system) above the baseline. Smaller increases were observed for the MPR typology (ranging between $3 \%$ for the rice-wheat system under CA to $22 \%$ for the diversified and intensified system) and again for the MWR and WR typologies, which did not differ greatly in the size of the increase in farm system cash balance from the baseline (ranging between 3-4\% in the baseline under CA to 7$12 \%$ in the intensified rice-wheat-mungbean system under CA). The potential farm-level benefits of improved crop management practices are much greater for less well-resourced farms for whom the yield gap is greater.

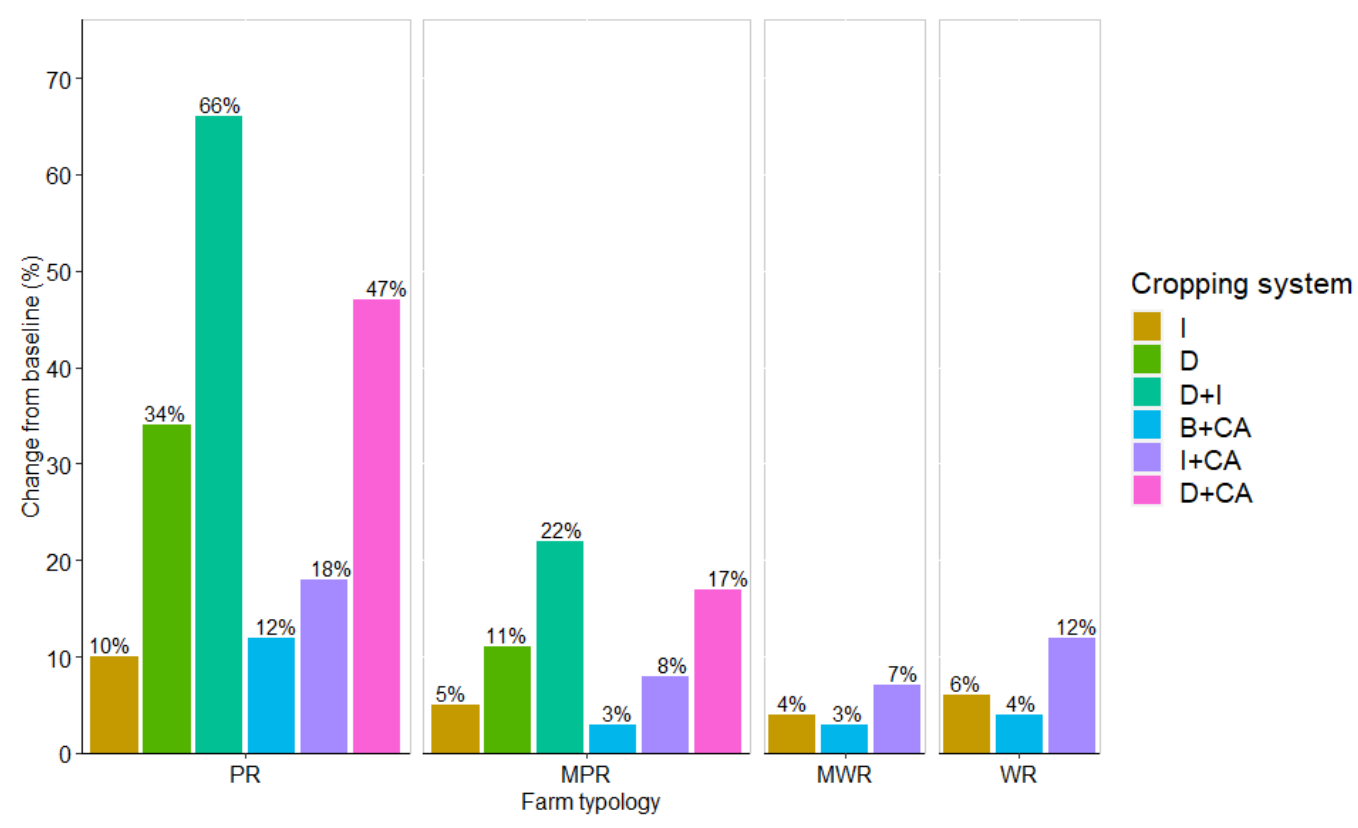

Figure 3. Percentage change in annual farm cash balance for each farm typology under six cropping system scenarios relative to the rice-wheat baseline. $\mathrm{I}=$ intensification, $\mathrm{D}=$ diversification, $\mathrm{I}+\mathrm{D}=$ intensification + diversification, $\mathrm{CA}=$ conservation agriculture 
Beletse, Laing et al., Farm-level effects of changing crop management using the Crop Livestock Enterprise Model (CLEM) in India

\section{CONCLUSION}

We used simulation modelling to demonstrate the value of integrating different crop management practices on farm-level economic productivity, cash balance and labour requirements for four farm typologies across northern India. In particular, we have demonstrated the potential for cropping system intensification, diversification or a combination of the two to increase productivity and profitability, at the same time noting that cropping system intensification in particular increases household labour requirements. These increases can be offset by the introduction of conservation agriculture practices, however doing so reduces men's but not women's labour requirements. Relative to the baseline system all the alternative cropping system management scenarios increased farm cash balances, by between 3 and 66\%. The CLEM model enabled us to integrate crop, livestock, labour and economics, and assess the economic benefits of cropping system interventions for different farm typologies. These long-term (20 year) analyses have the potential to inform researchers, extension agents, farmers and other stakeholder about the benefits and potential risks of improved crop management practices. Additional research activities could investigate a broader suite of farming typologies across the north-Indian cereal growing belt, and also examine additional potential changes to crop management practices, for example by examining practical ways for policymakers to support farmers to reduce their reliance on heavily-irrigated production systems while still producing staple cereal and high-value crops for consumption within India.

\section{ACKNOWLEDGMENTS}

This work was funded by the Sustainable Development Solutions Network of the United Nations. The authors are grateful to the expert advice provided by senior research scientists from CIMMYT in South Asia and the Indian Council of Agricultural Research at Meerut, Uttar Pradesh, India, and to Dr Elizabeth Meier and Dr Di Mayberry from CSIRO for internally reviewing this manuscript. The authors acknowledge the APSIM Initiative which takes responsibility for quality assurance and a structured innovation programme for APSIM's modelling software, which is provided free for research and development use (see www.apsim.info for details).

\section{REFERENCES}

Gathala, M.K., Laing, A.M., Tiwari, T.P., Timsina, J., Islam, M.S., Chowdhury, A.K., Chattopadhyay, C., Singh, A.K., Bhatt, B.P., Shrestha, R., Barma, N.C.D., Rana, D.S., Jackson, T.M., Gerard, B., 2020. Enabling smallholder farmers to sustainably improve their food, energy and water nexus while achieving environmental and economic benefits. Renewable and Sustainable Energy Reviews 120, 2020.

Holzworth, D.P., Huth, N.I., deVoil, P.G., Zurcher, E.J., Herrmann, N.I., McLean, G., Chenu, K., van Oosterom, E., Snow, V., Murphy, C., Moore, A.D., Brown, H., Whish, J.P.M., Verrall, S., Fainges, J., Bell, L.W., Peake, A.S., Poulton, P.L., Hochman, Z., Thorburn, P.J., Gaydon, D.S., Dalgliesh, N.P., Rodriguez, D., Cox, H., Chapman, S., Doherty, A., Teixeira, E., Sharp, J., Cichota, R., Vogeler, I., Li, F.Y., Wang, E., Hammer, G.L., Robertson, M.J., Dimes, J., Carberry, P.S., Hargreaves, J.N.G., MacLeod, N., McDonald, C., Harsdorf, J., Wedgwood, S., Keating, B.A., 2014. APSIM - evolution towards a new generation of agricultural systems simulation. Environment Modelling Software 62, 327-350.

Lisson, S., MacLeod, N., McDonald, C., Corfield, J., Pengelly, B., Wirajaswadi, L., Rahman, R., Bahar, S., Padjung, R., Razak, N., Puspadi, K., Dahlanuddin, Sutaryono, Y., Saenong, S., Panjaitan, T., Hadiawati, L., Ash, A., Brennan, L., 2010. A participatory, farming systems approach to improving Bali cattle production in the smallholder crop-livestock systems of Eastern Indonesia. Agricultural Systems 103, 486497.

Lopez-Ridaura, S., Frelat, R., van Wijk, M. T., Valbuena, D., Krupnik, T.J., Jat, M.L., 2018. Climate smart agriculture, farm household typologies and food security An ex-ante assessment from Eastern India. Agricultural Systems 159, 57-68.

McDonald, C.K., MacLeod, N.D., Lisson, S., Corfield, J.P., 2019. The Integrated Analysis Tool (IAT) - A

model for the evaluation of crop-livestock and socio-economic interventions in smallholder farming systems. Agricultural Systems 176 (2019) 1026592

R Core Team. R: A Language and Environment for Statistical Computing; R Foundation for Statistical Computing: Vienna, Austria, 2021. Available online: https://www.R-project.org/ (accessed on 05 July 2021).

Sterman, J.D., 2000. Business dynamics: systems thinking and modelling for a complex world. McGraw Hill, Boston, USA, 1008 pp.

Ward, P.S., Bell, A.R., Droppelmann, K., Benton, T.G., 2018. Early adoption of conservation agriculture practices: Understanding partial compliance in programs with multiple adoption decisions, Land Use Policy 70, 27-37. 